\title{
SHIFTER NO CINEMA: O HOMEM E O ANIMAL EM CENA
}

Shifter in the Cinema: The Man and the Animal On the Scene

\section{Ana Lúcia Machado da Silva}

(UNIP, Brasil)

\begin{abstract}
Resumo
Shifter é um termo empregado na literatura paranormal americana para referir à personagem que se transforma em animal. Essa literatura passou a influenciar o cinema, como visto na série Crepúsculo (2008, 2009, 2010, 2011, 2012) e em A garota da capa vermelha (2011). Com base na pergunta até que ponto a condição shifter leva a uma abertura para a animalidade, a discussão fundamenta-se nos Estudos Animais e busca caracterizar a personagem shifter, bem como comparar essa personagem com a metamorfose ocorrida no filme ícone A marca da pantera, da versão de 1982.
\end{abstract}

Palavras-chave: Personagem shifter | Animalidade | Metamorfose.

\begin{abstract}
Shifter is a term employed in the American paranormal literature to refer to a character who transform itself in an animal. This literature influenced cinema, like it can be seen on Twilight (2008, 2009, 2010, 2011, 2012) and in Red Riding Hood (2011). On the base of the question: To what extent the condition of a shifter leads to an opening to animality? The discussion here is grounded on the Animal Studies and it searches to define the shifter, in order to compare this character with the metamorphosis occurred in the iconic film Cat People, version of 1982.
\end{abstract}

Keywords: Shifter Character | Animality | Metamorphosis. 
Shifter designa mudança de uma personagem humana em animal não humano. Esse termo vem sendo empregado em textos literários americanos e significa, basicamente, a condição de uma personagem em se transformar em animal. O shifter é visto, também, no cinema, como na série Crepúsculo (2008, 2009, 2010, 2011, 2012) e no filme A garota da capa vermelha (2011), nos quais há personagem que vira lobo.

A criação de história de shifter - bem como o termo “shifter"- está crescendo desde a primeira década do século XXI. Encontra-se grande número de publicação de literatura paranormal americana e fanfics, estendendo-se a filmes, séries televisivas ${ }^{26}$, games. A metamorfose está inserida em ficções diversas na história cultural, não sendo, então, novidade; porém as narrativas de shifter apresentam peculiaridades diferentes.

Ressalta-se que essa literatura não remonta à fábula nem retrata um viés alegórico ou naturalista. Assim, não segue histórias tradicionais, em que os animais reiteram estereótipos ou podem representar-se simbolicamente. Não se trata também de narrativas com personagens animais humanizados ou simulacros de humanos. As personagens shifters não são animais não humanos com características humanas; ou, no outro extremo, igualmente não são personagens animais mais humanos do que os humanos.

Essa literatura não se destina à criança - ao contrário das fábulas, por exemplo - e, segundo critérios estéticos, não se iguala a obras como $A$ metamorfose, de F. Kafka, $A$ paixão segundo G.H., de C. Lispector, ou O livro das feras, de P. Highsmith. Na verdade, essa literatura de shifter destina-se ao público adulto, principalmente àquele habituado aos romances "água com açúcar" de banca de jornal e que ampliou ou migrou para a literatura shifter.

Enfim, são obras enquadradas como paranormais, eróticas e, muitas delas, homossexuais masculinas. São consideradas paranormais pela presença de personagem shifter pantera, leão, cão etc., com destaque ao shifter lobo; dragão ou shifter dragão; fae (fada tanto feminina quanto masculina); vampiro (são inúmeras as histórias com a presença concomitante de shifter e vampiro), anjos (ou demônios).

O enredo desenvolve-se dos relacionamentos amorosos entre homem/mulher, homem/homem e mulher/mulher, desde que um dos pares seja shifter. Determinadas narrativas são bizarras ao tratar de um relacionamento amoroso entre, por exemplo,

26 Entre as produções televisas, constam a série americana Teen Wolf, com estreia em 2011, com personagem shifter, e a série Animal, com apenas uma temporada em 2014, pelo canal GNT, em que a teriantropia é considerada um distúrbio. 
shifter coelho e shifter dragão. Tais histórias de amor, em geral, possuem um cenário de fundo de suspense, com gênero policial e/ou de apenas de violência. São poucas aquelas com fundo psicológico ou questão social.

Entre as autoras, destacam-se A. J. Jarrett, Lynn Hagen, Stormy Glenn e tantas e tantas outras com seus nomes e/ou com pseudônimos, cujas obras possuem publicação impressa, mas principalmente versão digital ebook.

As obras são traduzidas em várias línguas, incluindo português e espanhol, e divulgadas em blogs. Contudo, o maior acesso a elas deve-se à tradução e à divulgação não autorizadas. Por meio das postagens nesses mesmos blogs, verificam-se a extensão de países leitores e que o público se constitui basicamente de leitoras.

Assim, as produções fílmicas Crepúsculo e A garota da capa vermelha, cujas estreias ocorreram entre o final e o início das primeiras décadas deste século, têm influência dessa atual literatura. Em contraponto, o filme $A$ marca da pantera, da versão de 1982, foi selecionado para este estudo por ser um ícone do gênero de história de metamorfose, mas sem se incluir na nova demanda da narrativa de shifter.

Nesse contexto, são dois os objetivos deste estudo. Um deles é caracterizar a personagem shifter e o outro consiste em comparar essa personagem shifter com a metamorfose ocorrida no filme $A$ marca da pantera (1982), partindo da pergunta: até que ponto a condição shifter leva a uma abertura para a animalidade?

Para chegar a resposta e atender aos objetivos, este estudo insere-se no campo de pesquisa Estudos Animais, cujas temáticas concernem ao animal propriamente dito, à discussão sobre animalidade e à relação entre homens e animais não humanos. Devido às referências sobre animalidade de Foucault, concepção de devir-animal de Deleuze e Guattari, estudos zoontológicos de Wolfe, entre outras, a fundamentação teórica constituise híbrida com caráter transdisciplinar. Assim, nesse campo, segundo Maciel (2008; 2011), a abordagem vai desde a intersecção entre humanos e animais não humanos, com inflexão filosófica, ficções do animal e animalidade por meio de textos zooliterários diversos até o enfoque biopolítico dado às relações entre animalidade e soberania, corpo e imaginário. 


\section{Shifter e sua constituição mórfica}

A transformação em animal das personagens indicadas neste estudo ${ }^{27}$ induz ao pressuposto da condição primeira de hominalidade. Ou seja, a noção de hominalidade é confrontada com a de animalidade e cria o questionamento sobre até que ponto a condição shifter dessas personagens leva a uma abertura para a animalidade.

O confronto homem x animal não humano é decorrente do pensamento ocidental, principalmente da demonização dos deuses antigos e pagãos pelo cristianismo, da consolidação cartesiana sobre a supremacia identitária entre pensamento, consciência e linguagem, dos quais os animais não humanos são desprovidos, bem como da atribuição hegeliana à consciência de espírito.

A teriantropia - entendida como forte ligação entre homens e animais - não é aceita na corrente ocidental e, por consequência, o animal passa a ser considerado o Outro. $\mathrm{Na}$ distinção lúcida de Benedito Nunes (MACIEL: 2011), o homem da cultura ocidental se opõe ao animal e ao primitivo, que são considerados o Outro. Assim, o animal é o Outro. Ao contrário do homem, o animal não humano vive no meio da natureza, aliena-se da cultura e é submetido aos homens. Nessa submissão, o animal, que não tem instinto de maltratar, sente dor. Assim, o primitivo - o índio, o selvagem - é o Outro; o segundo Outro por possuir "mentalidade primitiva", na concepção antropológica tradicional (cf. LÉVYBRUHL: 2008). Esse tipo de mentalidade significa que o índio não apenas está ligado à natureza como também participa dela com potencialidade mística.

Na síntese feita por Dominique Lestel (MACIEL: 2011: 29), homem e animal não humano distinguem-se por meio dos seguintes sinais:

- O número de cromossomos, comumente evocado, passa de 48 (como os dos chimpanzés atuais) para 46 nos hominídeos, há 25 milhões de anos.

- A tíbia é alongada e o bipedalismo adquirido. Com seus quadris estendidos e sua bacia de chimpanzé, os australopitecos encarnam uma etapa crucial no processo de hominização.

- De importância variável, a melhora da visão, o pé transformado, a mão liberada, o maxilar modificado para uma dentição que permite mastigar

270 jovem rapaz Jacob Black, da série Crepúsculo, é um shifter lobo; Cesare, em A garota da capa vermelha, surpreende o público ao ser o lobo da história; e Irena Gallier transforma-se em pantera, no filme $A$ marca da pantera. 
alimentos variados e um focinho achatado.

- O uso generalizado da ferramenta: mais complexas que aquelas construídas a partir da eliminação de alguns fragmentos de sílex, os famosos "esferoides", essas ferramentas de punho remontam a 3 milhões de anos.

- A fala e o uso de símbolos usualmente considerados as maiores características da "saída" da animalidade. O Homo erectus já podia falar. Ele possuía ao menos habilidades psicológicas e cognitivas. Os crânios mostravam uma cavidade que corresponde bem à área de Broca. Jeffrey Laitman considera até mesmo que o Homo erectus possuía a laringe requerida, à diferença do australopiteco, que tinha ainda a garganta de um macaco.

As personagens shifters nas narrativas literárias são seres humanos. Físicobiologicamente, são bípedes, capazes de usar as mãos e possuem aparelho fonador para a fala. Na esfera cognitiva, são inteligentes e exercem diversas funções no campo do trabalho. Socialmente, são interativas umas com as outras, vivem em comunidade e enfrentam as desigualdades socioeconômicas. Trata-se de homo erectus, que nasce, tornase adulto, é produtivo, casa-se e morre.

Enfim, a personagem shifter possui todas as características humanas:

1. dados orgânicos: saúde e estado funcional.

2. dados psicológicos: identidade, auto-estima, aprendizado.

3. dados sociais: relacionamento, privacidade, sexualidade.

4. dados comportamentais: hábitos, vida profissional, lazer.

5. dados materiais: economia privada, renda, habitação.

6. dados estruturais: posição social, significado da própria vida.

No entanto, diferente do ser humano, essas personagens têm uma característica incomum ou até mesmo fantástica; elas passam pelo processo de metamorfose: mudam sua condição de ser humano para animal não humano.

No filme da série Crepúsculo, a personagem shifter é o jovem Jacob Black, que, ao chegar aos 15 anos passa pela primeira vez pela mudança, transformando-se em lobo. Sua constituição física passa a ser semelhante à de um lobo: quadrúpede, focinho alongado, pelo por todo o corpo. A diferença está no tamanho, maior do que um lobo comum. Além disso, os sentidos ficam mais aguçados, geralmente o olfato e a audição, o instinto para 
caça aumenta e a defesa é ampliada, abrangendo tanto a autodefesa quanto a defesa das pessoas próximas e queridas.

$\mathrm{Na}$ literatura, quando em condição de animal (lobo, jaguatirica ou outro), a personagem tem mais energia e força e sente necessidade de estar em grupo. Essas características são aferidas no shifter Jacob Black.

Não obstante, tais mudanças físicas são as mesmas dos shifters da literatura.

Outro aspecto constituinte mórfico é a própria condição shifter. Em uma das obras literárias, uma das personagens shifters explica:

Ninguém está certo de quando tudo começou, ou mesmo quem foi o primeiro shifter lobo conhecido. Ser um shifter é apenas uma coisa aleatória, como uma pessoa que tem olhos azuis. Está apenas em seu DNA (...) um shifter nasce, não se transforma, e pode mudar sempre que quiser. Não é escravo da lua. (JARRETT, A. J. Matilha Nehalem, vol 14, p. 66-67)

Em outras palavras, a metamorfose é natural e genética. Não é uma opção pessoal nem garantia de que os descendentes também serão shifter.

A transformação física e a herança genética, do mesmo modo, são fatores constituintes nos filmes A garota da capa vermelha e A marca da pantera.

No primeiro filme, a personagem shifter é Cesare, um homem adulto, que muda para lobo. Ele, em sua forma lupina, igualmente tem pelos no corpo, focinho alongado e é quadrúpede, e sua força supera a de um homem e a do lobo comum. Sua mudança é devido também ao fator genético, mas o diferencial está na primogenitura; apenas o(a) filho(a) primogênito(a) é um shifter, com condição para passar pela metamorfose.

No segundo filme, a personagem Irena Gallier, jovem mulher, descobre na fase adulta sua herança familiar: transformar-se, no caso, em pantera. Seu animal não supera o animal pantera comum; Irena Gallier torna-se tal qual uma pantera em sua constituição mórfica.

De forma geral, personagem shifter tem controle sobre quando mudar:

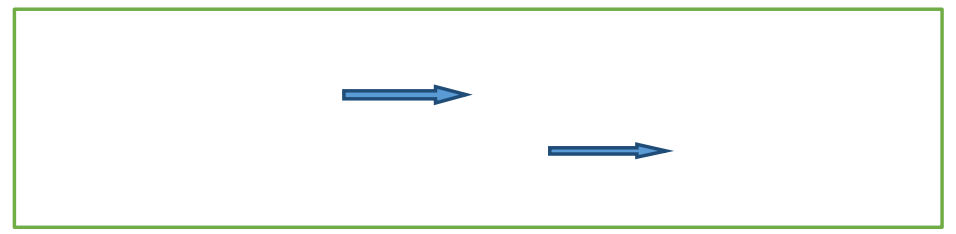

Retomando o questionamento inicial sobre até que ponto a condição shifter leva a 
uma abertura para a animalidade, apenas a constituição mórfica da personagem Irena Gallier corresponde à naturalidade da constituição do animal (pantera). As outras personagens passam a ter características mórficas de animal, mas estas ultrapassam em tamanho e força do animal (lobo) comum.

Outra conclusão parcial é a influência da literatura paranormal no cinema. Além da série Crepúsculo, cuja personagem corresponde às características mórficas de um shifter literário, não se pode esquecer que a história $A$ garota da capa vermelha é uma atualização do conto Chapeuzinho Vermelho, de Charles Perrault, do século XVII. A atualização consiste justamente na figura do lobo. O lobo deixa de ser personagem animal e passa a ser um shifter, ou seja, um humano que por herança genética pode mudar para a condição animal não humano.

\section{Comunidade híbrida}

Nas narrativas fílmicas, humanos e shifters se interagem e formam uma comunidade híbrida. Torna-se necessário saber, segundo enfoque da ecologia política, que relação as comunidades humanas podem manter com as comunidades animais.

Essa comunidade híbrida opõe-se à noção de vida selvagem. A personagem shifter convive com humanos e, nesse caso, em ambiente considerado civilizado. Não se tem, então, oposição vida selvagem x civilização nas narrativas, e a convivência ocorre, portanto, em ambiente urbano.

Vida urbana, conforme Papageorgiou (1976), engloba aspectos ambientais, habitacionais, urbanos, sanitários, sociais. Sobre o ambiente, este se relaciona, por exemplo, à domesticação e domiciliação; no caso da habitação, trata-se desde a disponibilidade espacial até as condições de habitabilidade; os aspectos urbanos, por sua vez, envolvem concentração populacional, comunicação, segurança, entre outras situações; quanto aos sanitários, assistência médica e mortalidade fazem parte dessa questão urbana; e, finalmente, sobre os aspectos sociais, sistemas de classes, condição de trabalho, nível socioeconômico, consumo, necessidades, sexualidade, lazer são alguns exemplos de preocupação da vida urbana.

As três personagens metamórficas compartilham sua existência com humanos em uma ruptura das dicotomias homem x natureza (selvagem). Se há convivência entre 
homem e animal nas narrativas fílmicas, essa convivência se dá na vida urbana, que se contrapõe à vida selvagem e aponta para a animalidade típica urbana, que é o animal doméstico.

A noção de domesticação recupera, no mínimo, três fatores relevantes, como indicados por Haudricourt e Dibie (cf. LESTER, In: MACIEL: 2011). Um deles é sobre a apropriação do animal pelo homem. Sobre esse fator, as personagens humanas não se apropriam do shifter. Outro fator é a utilização do animal pelo homem. Da mesma forma, nas narrativas, não se verifica tal fator. Por fim, a familiarização do homem e do animal. Nas narrativas, os humanos desconhecem a existência de shifter em sua comunidade. Na análise, enfim, os shifters não são animais domésticos.

Na verdade, a noção de animal doméstico não é conhecida por todos os povos ou em todas épocas históricas. Os indígenas, por exemplo, encontraram animais domésticos pela primeira vez com o advento da colonização. O impacto, em muitos casos, foi traumatizante.

O shifter lobo Jacob Black, da série Crepúsculo, faz parte da comunidade híbrida, dividindo-a com humanos, que poucos conhecem sua capacidade de se metamorfosear. No caso dele, a alteridade é dupla. Ele é o Outro por ser animal e por sua descendência indígena. Contudo, devido ao desconhecimento dos humanos sobre a existência de shifter, a personagem convive com eles, ajudando a consolidar a comunidade.

Enfim, as narrativas shifters não fazem parte dos movimentos ecológicos atuais e, também, não refletem a proliferação dos bichos de estimação instaurada em um novo tipo de relação com os animais na cultura, em que o jogo de oposição, transformado profundamente na segunda metade do século XX, substitui o par animal doméstico/animal selvagem pelo par animal de estimação/animal a ser preservado.

Ao pensar na configuração do animal em comunidade com o humano, não é apenas o animal doméstico que pode conviver com o humano; os animais selvagens também podem figurar nesse tipo de comunidade. Na vida urbana, em que se instaura essa comunidade, o selvagem (lobo, pantera) só se relaciona com a comunidade por meio do zoológico.

Zoológico começa sua expansão com a colônia europeia e sua localização serve de espaço para exibição e estudo de animais provenientes de diversas regiões. Zoológico e cidade tornam-se espaços em que a natureza fica inserida em situações opostas, tensas e complexas. No dizer de Bravo (In: MACIEL: 2011: 226): 
O zoológico opera como fragmento de vida selvagem incrustado no espaço urbano do qual se aproxima e se distingue, roçando-o e limitandoo. O crescimento da vida urbana distanciou os animais de espaço comum (compartilhado) com os humanos e os confinou a celas onde podiam ser observados pelas massas urbanas.

A grade passou a ser servir como primeiro contato entre o homem e o animal, funcionando como união e separação entre dois universos opostos, porém contíguos e em contato.

Nas narrativas fílmicas, encontram-se dois pontos de vista opostos sobre o zoológico. O zoológico, que passa a representar a relação animal e homem na vida urbana, raramente faz parte do núcleo dramático nas narrativas literárias paranormais. Assim, como no modelo dessas narrativas, o zoológico é completamente ignorado na série Crepúsculo.

Quanto ao filme A garota da capa vermelha, a história é ambientada na Idade Média, antes da proliferação desse espaço gradeado.

A situação é extremamente oposta no filme $A$ marca da pantera. Nesse filme, o zoológico é cenário fundamental tanto para o desenrolar da história quanto para a decisão final da personagem Irena Gallier, que opta pela condição animal, mantendo-se pantera e presa como animal selvagem no zoológico.

Referência a zoológico, portanto, não caracteriza a animalidade nas narrativas shifters. Na verdade, referência a zoológico leva à conscientização de que a personagem shifter é uma mistura de homem e animal, mas o shifter leva uma convivência cotidiana e comum a do homem.

\section{Shifter: abertura para a animalidade?}

O hibridismo não está apenas na convivência entre shifter e humanos em uma comunidade. O shifter é uma personagem que possui corpo híbrido de homem e animal. Sua constituição corporal oscila entre a precariedade do corpo, com base em sua fisiologia, e a abertura para a animalidade.

A imagem é um lobo (ou pantera) de corpo antropomórfico, cuja transformação tem forma provisória e o corpo modificado parte e volta para o humano. Assim, ocorre com as 
personagens deste estudo. Nesse ponto de vista, conforme Bataille (1993: 19), a animalidade é "o imediatismo ou a imanência”.

Os corpos híbridos e metamórficos residem na sua pele, em transformação daquilo que não é o sujeito nem o objeto. Como chama Julia Kristeva (cf. JORGE In: MACIEL: 2011), é uma aparição abjeta: corpo com uma presença extremamente outra. O homem se transforma no Outro.

Transformado, o shifter lobo Jacob Black, da série fílmica Crepúsculo, tem ferocidade ou força biologicamente inscrita no corpo e se converte a um grande sistema sensorial, o qual se torna mediador na relação do shifter com o mundo. No entanto, a personagem - na pele de lobo - mantém sua identidade humana, uma vez que ela continua com os traços essenciais que são inferidos ao ser humano, tais como a memória, inteligência, raciocínio lógico e linguagem. De forma geral, em condição animal, essa personagem não perde a consciência.

Em A garota da capa vermelha, o shifter lobo igualmente se reveste da pele de animal sem perder sua condição de hominalidade, mas é considerado uma ameaça. Não se pode esquecer que se trata de uma história ambientada na Idade Média, época de recusa à animalidade e que esta é relacionada à demonização.

Ser shifter, por conseguinte, é ser um demônio e representar todos os perigos, mal, luxúria, violência, loucura, enfim, a designação da bestialidade, que é deslocada para a parte animal que existe em todo ser humano. Trata-se, como explica Foucault (2005), da dimensão negativa da animalidade na cultura ocidental e, em especial, no contexto medieval.

A metamorfose das personagens expõe apenas a superfície da animalidade sobre a pele. As personagens são, então, a textura da animalidade; repousam na textura, na película. Enfim, a animalidade existe enquanto pele.

Diferente da personagem shifter, Irena Gallier, transformada em pantera, tem existência imanente e imediata no que diz respeito à sua incapacidade de distinguir objeto, ou seja, torna-se animal que não percebe diferença entre ele próprio e seu entorno.

Na explicação de Bataille (1993: 24),

há para o lobo [no caso de Irena Gallier, para a pantera] continuidade do mundo e de si mesmo. Diante dele se produzem aparições atraentes ou angustiantes; outras aparições não correspondem nem a indivíduos de mesma espécie, nem a 
alimentos, nem a nada de atraente ou de repulsivo; a partir daí, aquilo de que se trata não tem sentido, ou o tem como signo de outra coisa.

Na forma pantera, Irena Gallier perde a consciência, não compreendo diferentes objetos nem lhes dá sentidos. Ela vivencia experiências sem distinções, sem consciência, sem palavras.

As personagens shifters compartilham com o público a sensação - aisthesis, na concepção clássica. Irena, por sua vez, em sua forma animal, não mostra sua exploração sensível nem faz inventário das formas de vida e de sensibilidade. Em sua forma animal, há o deslocamento para a identidade animal. A fronteira animal não humano e humano é rompida e, nessa ruptura, a pantera não responde e não representa o simbólico.

\section{Erotização e campo do afeto}

A animalidade nos filmes coincide com o desejo sexual. Afinal, a animalidade é inerente à pele. Porém, paradoxalmente, o erotismo é um fator diferenciador entre animal e homem.

O homem saiu de sua animalidade e chegou à hominização devido a determinados critérios (cf. BATAILLE: 1993). Um deles é o trabalho, o qual é uma atividade essencialmente humana com ação compensatória. A arte é considerada outro critério diferenciador, por meio da qual o homem se atribui uma imagem poética e consolida sua hominização. Outro critério é a erotização, que é própria do homem.

Os humanos são animais que tendem a considerar os animais não humanos como meio para atingir um fim, em geral, utilitário, como alimentação e vestuário. Na literatura paranormal, a condição shifter torna-se pretexto para criação de histórias eróticas. A erotização está subjacente e é a base das metamorfoses.

A personagem shifter sofre o calor do acasalamento ao encontrar seu companheiro, passando a ter desejos sexuais que precisam ser satisfeitos para não causar dor, loucura ou até mesmo morte. O desejo sexual torna-se hiperbólico, porém esse acasalamento não se restringe ao ato sexual, uma vez que está disfarçado de amor eterno.

Faz parte do destino de um shifter ter um companheiro (mate, em inglês). Este é descoberto pelo cheiro ao exalar um odor único, só identificado pelo shifter. Caso o casal seja shifter, o reconhecimento é instantâneo; caso apenas um seja shifter, este identifica no humano seu companheiro. O casal, após o reconhecimento, é destinado a ter um final feliz 
(happy end), tal como ocorre em história água com açúcar.

O shifter Jacob Black, na série Crepúsculo, marcou cenas com forte sensualidade ao aparecer, por exemplo, sem camisa. Ele, como os shifters literários, identifica sua companheira de vida na personagem Renesmee ${ }^{28}$, filha do casal central da série. Em Crepúsculo, tal identificação é designada de imprinting.

No filme A garota da capa vermelha, a sexualidade, o ato sexual e o desejo sexual não são centrados na personagem shifter, mas na personagem principal, na própria garota do título. Como já foi dito, o shifter é uma ameaça e, como tal, desprovido de caráter para se tornar o mocinho da história e, por consequência, viver um amor eterno.

N'A marca da pantera, Irena Gallier transforma-se em uma pantera, que, na cultura ocidental, é símbolo de sensualidade. $\mathrm{O}$ ato sexual não apenas leva à transformação, mas também à morte do parceiro. Em forma animal, Irena Gallier não tem consciência de seu estado anterior - a de hominização, ultrapassando a textura de seu animal.

\section{Considerações finais}

A crescente proliferação da literatura shifter reflete na literatura e no cinema com a presença de personagem shifter. A metamorfose nessas produções atuais é marcada pela superficialidade da pele, mais como uma causa ou um cenário para criação de histórias, principalmente eróticas.

Essa superficialidade é refletida no ambiente em que as narrativas acontecem. Esse ambiente ou cenário é a cidade, a qual, devido ao seu ecossistema antrópico, possui o mais elevado grau de artificialidade. Nesse contexto, shifter e humanos constituem uma comunidade híbrida, em que animal doméstico e zoológico não fazem parte, uma vez que shifter não se caracteriza como animal doméstico, pois a personagem possui uma vida urbana compartilhada com os humanos.

Na comparação entre narrativa shifter e o filme A marca da pantera, constatam-se diferenças e até mesmo oposições entre as histórias. Apesar de sua carga forte de erotismo, mas talvez justamente por causa dessa carga, A marca da pantera tornou-se um ícone de

28 Na literatura paranormal, os companheiros são descobertos na fase adulta. Porém, não são raras as obras em que o companheiro é descoberto enquanto este ainda está na fase infantil ou adolescente. Nesse caso, há espera para a união do casal. 
discussão sobre a relação homem x animal no que concerne à luta contra o instinto, em especial, o instinto sexual. Esse filme diverge dessa onda de produção shifter, uma vez que a bestialidade ou a perda de hominalidade realmente diferenciam homem e animal não humano. Ou em outros termos, o público tem de fato a aproximação homem/animal.

\section{Referência bibliográfica}

BATAILLE, Georges. Teoria da religião. São Paulo: Ática, 1993.

FOUCAULT, Michel. História da loucura. São Paulo: Perspectiva, 2005.

LÉVY-BRUHL, Lucien. A mentalidade primitiva. São Paulo: Paulus, 2008.

MACIEL, Maria Esther. $O$ animal escrito: um olhar sobre a zooliteratura contemporânea . São Paulo: Lummes, 2008.

(Org.). Pensar/escrever o animal: ensaios de zoopoética e biopolítica.

Florianópolis: Editora da UFSC, 2011.

PAPAGEORGIOU, J.C. Quality of life indicators. Int. J. environ. Stud.,9: 177-86,1976. 